\title{
APPENDIX II. DRILLING OPERATIONS, LEG 25, DEEP SEA DRILLING PROJECT
}

\author{
John R. Shore, Chevron Oil Field Research Co., La Habra, California
}

\section{INTRODUCTION}

The Glomar Challenger and its equipment have been well described in prior technical reports. Briefly, the vessel is self propelled, dynamically positioned, and diesel-electric powered (DC) for both drilling and propulsion. Satellite navigation is used to accurately determine geodetic position. Load ratings of the derrick and hoisting equipment are 500 tons.

The purpose of this chapter is to review the drilling and coring equipment, techniques, and closely associated operations used on Leg 25 (June 28 to August 22, 1972). During this 57-day cruise, the Challenger traveled 5408 nautical miles and drilled 13 holes at 11 sites. Drilling penetrated 4253 meters of ocean sediments, of which 33 percent was cored with a total recovery of 57 percent. Drilling depths ranged from 26 to 1174 meters below the sea floor, and the average program consisted of taking four cores every 100 meters. No hydrocarbons or gas shows were encountered. Distribution of total leg time was $49.2 \%$ cruising, $27.5 \%$ drill pipe handling, $8.2 \%$ coring, $6.4 \%$ drilling, and $8.7 \%$ other (in port, misc. operations, etc.).

\section{VESSEL PERFORMANCE}

Performance of the vessel and its attendant systems is included here because of its influence on the drilling and coring activities.

Operations were conducted in water depths of 944 to 5082 meters, which fall within the 900 to 6900 meter allowable operating range for drill string safety. Weather during the leg was generally moderate but "confused." The few days of storms while on site did not halt operations.

The cruising speed of the Challenger between sites averaged 8.5 knots, which, as mentioned in some of the published reports, is slower (these were as high as 12 knots) than for conditions more ideal than those found in the Indian Ocean. Consequently, this slower speed had a direct bearing on the time "allocated" for drilling and coring at each site.

The design of the Challenger permits drilling activities in 15 -ft (4.6 meters) seas, 40-knot winds, and 3-knot currents, all from one direction. Ideally, a vessel heading is selected so that position can be maintained with a minimum of vessel motion and thruster use. However, this was often prevented during Leg 25 by "confused seas," when swell, current, and wind came from different directions. At 9 of the 13 holes, swell trains averaging $9 \mathrm{ft}(2.7$ meters $)$ resulted in an average $6^{\circ}$ of roll (maximum, $10^{\circ}$ ), and an estimated heave of one meter. This made it difficult to keep constant weight on the bit and uniform torque on the drill string. On occasion, drill string motion from roll, pitch, heave, surge, and sway of the vessel resulted in the bit being jammed into the formation, even with bumper subs in the bottom-hole assembly. The result was poor core recovery and/or damage to bit teeth and bearings. Bit loads in excess of $35,000 \mathrm{lb}$ were witnessed at times, the normal load being 10,000 to $20,000 \mathrm{lb}$.

The dynamic positioning system of the vessel has three modes of operation: manual, semiautomatic, and automatic. Automatic, where the station and heading are maintained automatically by the computer, was the one normally used during drilling or coring. The system responded admirably, and vessel excursion while drilling averaged only 0.2 to 1.4 percent of water depth. This is well within operational limits of 3 percent (to prevent overstressing drill pipe). The limit was 5 percent for other operations. Computer component failures did occur during the leg but without detrimental effects except at Hole 248. There, manual positioning was used and twice during coring, vessel drift from the hole was sufficient to lift the drill string and give a false indication of a "drilling break" (formation change).

Beacons used for vessel positioning were single O.R.E. sonar beacons, weighted and having self-contained 6- or 12-day batteries. They were dropped to the ocean floor where they emitted a $13.5-$ or $16-\mathrm{KHz}$ pulse of $40 \mathrm{msec}$ duration every $2 \mathrm{sec}$. Two beacons used during the leg malfunctioned after 10 to 12 hours and required replacement. An interesting aspect was that the replacement beacons landed some 175 to 250 meters from the original ones, rather than the anticipated 60 to 90 meters. Although this "offset" can be accommodated by the positioning system, any beacon displacement much greater than this would have created positioning problems in rough seas.

The six hydrophones installed in the hull of the vessel (only three in use at any time) are peaked for reception of 13.5. or $16-\mathrm{KHz}$ sound waves from the O.R.E. ocean bottom beacons. Differences in arrival time to the various hydrophones, suitably preprocessed, enter the positioning computer where they are translated into signals that bring about correction of the ship's position. It was interesting to note that during the move in calm weather from Site 243 to nearby Site 244 , the hydrophones still picked up the beacon signal from a distance of $2400-2700$ meters. At Sites 245 and 248, noise from the bow thrusters periodically blanked out beacon signals to some of the hydrophones, making necessary either semiautomatic or manual vessel positioning. In at least one of these cases, signal loss was caused by thruster "wash" being driven under the port side of the vessel by a strong head-on current. 


\section{DRILLING EQUIPMENT}

\section{Bottom Hole Assemblage}

The bottom-hole assembly used at all holes of Leg 25 was the same as that used for previous legs, namely (from the bottom up): core bit, float sub, $81 / 4$-in. core barrel, three $81 / 4$-in. drill collars, two $81 / 4$-in. bumper subs, three $81 / 4$-in. drill collars, two $81 / 4$-in. bumper subs, two 8 1/4-in. drill collars, one 7 1/4-in. drill collar, one joint of $51 / 2$-in. heavy-weight drill pipe, and the regular 5 in. drill pipe. This assembly, from the $51 / 2$-in. heavy-weight drill pipe to the bit, weighs approximately $42,500 \mathrm{lb}$ in water. Components of the system are discussed in subsequent paragraphs.

\section{Core Bits}

Over the relatively few years of DSDP operations, tremendous strides have been made in developing more suitable coring bits designed to remain in satisfactory condition until scientific objectives are reached. One of the more important developments has been the development of bits having cutters with tungsten carbide inserts.

The bit selected for each hole during this leg depended primarily upon the formations that were anticipated; tooth length being particularly important. Long teeth were used for the softer formations, short teeth for the harder.

The 7 Smith bits used in drilling the 13 holes were 10 $1 / 8$-in. OD (outer diameter) and had either three or four cutters with tungsten carbide inserts. Four had sealed bearings. The water courses through the bits were 9/16-in. diameter with extended jet nozzles for better cleaning of the cutters. A bit summary shows the number of each type used, together with the rotating hours on each bit when taken out of service (Table 1).

The data in Table 1 indicates superior performance by the 4-cutter, sealed-bearing bits. Although this conclusion may be valid, a truly scientific comparison would consider all factors, such as variation of weight on bit, bit speed, formation hardness and abrasiveness, fluid circulation, etc. This comparison is beyond the scope of this article.

The average life for all seven bits was about $231 / 2$ rotating hours. Although from past experience, 40 rotating hours might be expected from sealed-bearing bits, vessel heave and hard formations were major factors in reducing this figure. Typical failures were broken or damaged bearings, chipped or missing teeth (tungsten carbide inserts), missing cutters (after drilling on basalt), and bent core throats. In one hole, the bit drilling efficiency was greatly reduced by having the cutters almost completely encased in clay-rich nanno chalk. After cleaning, it was satisfactory for use in the next hole (Figure 1).

\section{Core Barrels (Outer and Inner)}

The outer core barrel has the same dimensions as a drill collar: 8 1/4-in. OD, 4 1/8-in. ID (Inner Diameter) and 30 ft long. On the bottom, it has a bit sub containing a float valve assembly and a supporting bearing for the inner barrel. It also has a sub on top that contains the latch sleeve for preventing the inner barrel from moving upward during coring.
The inner core barrel is wireline retrievable, has dimensions of $31 / 2$-in. $(8.9 \mathrm{~cm})$ OD $\times 27 / 8$-in. $(7.3 \mathrm{~cm})$ ID $\times 34 \mathrm{ft}$ (10.4 meters) and is fitted with a removable plastic tube (for core containment) of 2.62-in. (6.7 cm) ID $X 31 \mathrm{ft}, 3$ in. (9.5 meters) long. Two types of core catchers can be run on the bottom of the inner barrel: a dog-type (with two styles of fingers) for softer formations and a slip type for harder formations. The barrel is designed to accept two dog-type catchers or a combination of a slip and dog-type. For extremely soft and soupy formations, a plastic sock is installed above a dog-type catcher. Results with various catchers are outlined in the section on techniques.

\section{Drill Collars}

Each drill collar has the dimensions previously indicated $(81 / 4$ in. $\times 41 / 8$ in. $X 30 \mathrm{ft}$.). The bottom three drill collars and the core barrel permit a maximum weight on the bit of approximately $16,000 \mathrm{lb}$. (in water). If the bottom two bumper subs are closed, this adds about $14,000 \mathrm{lb}$, for a grand total of $30,000 \mathrm{lb}$ on the bit.

Drill collars and bumper subs are made to withstand approximately $30,000 \mathrm{ft}-1 \mathrm{bs}$ torque during running. Once during the leg, pins and boxes were examined for cracks. They were (1) washed with drilling water, (2) cleaned with diesel oil, (3) sprinkled with barite (to absorb oil), (4) cleaned by air-driven brushes, (5) painted with Magnaglo solution, (6) magnetized, and (7) inspected under "black" light. No flaws were detected on the 13 collars and subs examined during the leg.

\section{Bumper Subs}

Bumper subs are essentially a telescopic joint capable of transmitting torque by means of a spline. Pressure integrity during stroking is maintained by a cartridge-type packing element in contact with a chrome-plated wash pipe. Four subs are placed in the drill string to compensate for vessel heave and keep a more or less constant weight on the bit.

Two factors cause difficulty in maintaining constant bit weight, even with bumper subs in the string: (1) long drill strings perform somewhat like a rubber band with a weight on the bottom, and the bit end can have axial amplitudes greater than the ship's heave; and (2) extension of the subs can only be estimated when drilling ahead.

The type of sub used on Leg 25 was the same as that used on previous legs-an $81 / 4$-in. Baash-Ross 6SI-PM-1 "unbalanced" model having a 5-ft stroke. An "unbalanced" sub tends to be extended by the pump pressure on the core barrel and bit during drilling or coring. This extending force partly compensates for the upward force caused by the bit being in contact with the formation.

Facilities and parts are available onboard for completely overhauling bumper subs. The cartridge-type packing element is normally changed after about $300 \mathrm{hrs}$. of service. Leg 25 was relatively free of trouble with subs. A galled wash pipe required changing, and one bumper sub was bent (at Site 247) in attempting to penetrate hard sediments without having lateral support for the bottom-hole assembly. 
TABLE 1

Bits Used on Leg 25 with Rotating Hours for Each

\begin{tabular}{c|c|c|c|c|c|c|c|c|c|c|c}
\hline \multicolumn{4}{c|}{3 Cutter } & \multicolumn{6}{c}{ 4 Cutter } \\
\hline \multicolumn{3}{c}{ Sealed Brg } & \multicolumn{2}{c|}{ Nonsealed Brg } & \multicolumn{3}{c|}{ Sealed Brg } & \multicolumn{3}{c|}{ Nonsealed Brg } \\
\hline $\mathrm{L}$ & $\mathrm{M}$ & $\mathrm{S}$ & $\mathrm{L}$ & $\mathrm{M}$ & $\mathrm{S}$ & $\mathrm{L}$ & $\mathrm{M}$ & $\mathrm{S}$ & $\mathrm{L}$ & $\mathrm{M}$ & $\mathrm{S}$ \\
\hline 0 & $1(13.5)$ & 0 & 0 & $1(13.1)$ & 0 & $1(51.6)$ & $\begin{array}{l}1(32.8)^{\mathrm{a}} \\
1(21.6)\end{array}$ & 0 & 0 & $1(17.4)^{\mathrm{b}}$ & $1(14.0)$ \\
\hline
\end{tabular}

Note: $\mathrm{L}=$ long tooth; $\mathrm{M}=$ medium tooth; $\mathrm{S}=$ short tooth

${ }^{a}$ Good for rerun, but lost in hole.

bLast bit used; good for rerun.

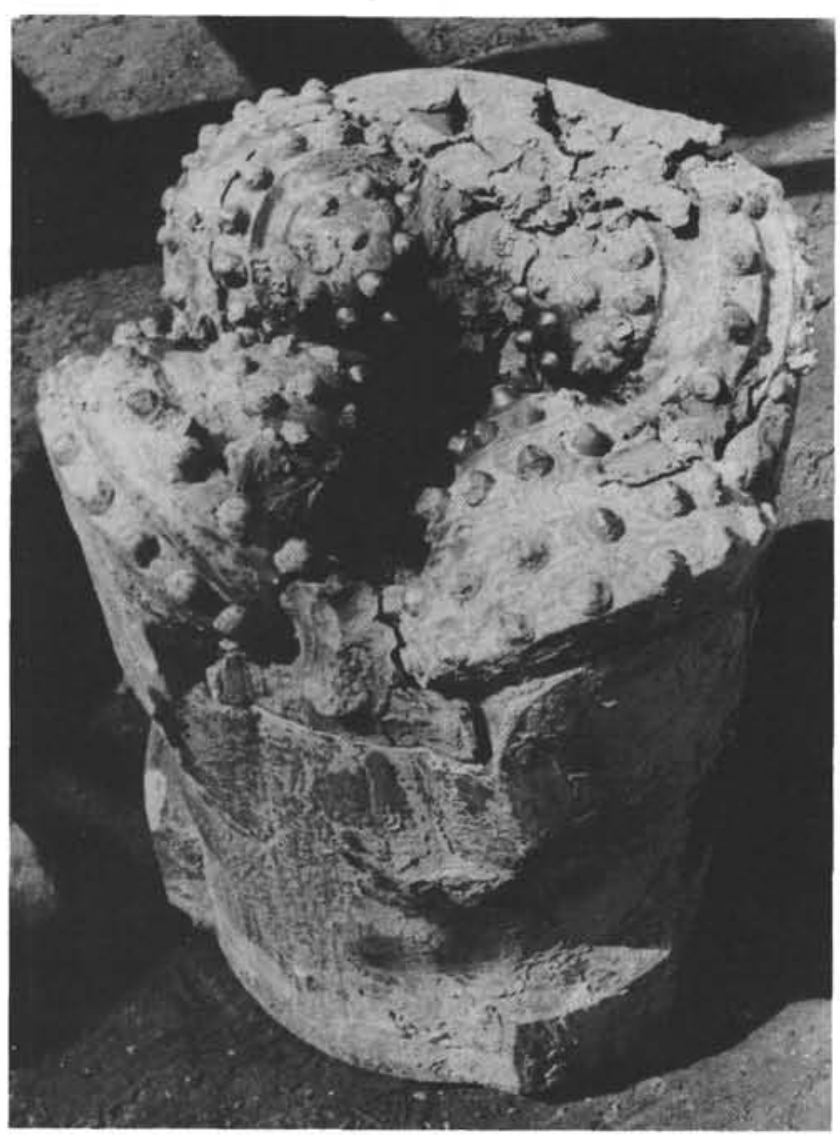

Figure 1. Bit balling after drilling clay-rich nanno chalkgumbo (Site 242).

\section{Drill Pipe}

The Grade S-135, drill pipe used has a 5-in. OD, and weighs $19.6 \mathrm{lb} / \mathrm{ft}$. Specifications are outlined in Table 2 . Each joint is externally upset and fitted with a modified 51 - $/ 2$-in., full-hole, flash-welded, $18^{\circ}$-taper tool joint.

No drill pipe failures occurred on Leg 25 . The S-135 pipe is known for its durability and excellent service record during the past several years of severe tension, torsion, and bending in a saltwater environment. The longest string used for the leg was $17,700 \mathrm{ft}$ (5866 meters), which is about 20 percent less than the maximum allowable $(22,000 \mathrm{ft})(6860$ meters). This maximum is based on full loading plus
TABLE 2

Drill Pipe Specifications

\begin{tabular}{lc} 
Minimum yield strength & $135,000 \mathrm{psi}$ \\
Tension load at minimum yield strength & $712,070 \mathrm{lb}$ \\
Torque at minimum yield strength & $74,100 \mathrm{ft}-\mathrm{lb}$ \\
Minimum collapse resistance & $15,640 \mathrm{psi}$ \\
Internal pressure at $87.5 \%$ minimum yield & $17,100 \mathrm{psi}$ \\
\hline
\end{tabular}

$100,000 \mathrm{lb}$ overpull in case of stuck pipe. Maximum tension applied during the leg approached $500,000 \mathrm{lb}$, when the pipe was temporarily stuck at Hole 241 .

The active drill string is carried in 94-ft strands ( 3 joints screwed together) in the horizontal pipe rackers just forward of the derrick floor. The capacity of this racker is $24,000 \mathrm{ft}$. (7400 meters). An additional $11,000 \mathrm{ft}$ (3350 meters) is stored below deck. The pipe is run into, and pulled out of, the hole by a dual elevator system rather than by conventional slips, to eliminate the possibility of failures from notches left by the slip teeth (stress risers). Automatic equipment makes pipe handling relatively easy, even during noticeable vessel motion.

The potentially most detrimental problem concerning drill pipe life is pitting from aerated salt water circulated as drilling fluid, which can cause stress corrosion fatigue-type failure. However, inspection and control procedures have eliminated this problem. These procedures include inspections by Tuboscope, flushing the pipe with fresh water before pulling, and periodic treatment using a corrosion inhibitor.

The standards used by Global Marine for grading drill pipe are those common to the petroleum industry. Wall thickness measurements to determine fatigue cracks, corrosion pitting, or other service-induced damage are initially made by a special Tuboscope instrument. This tool creates a magnetic field for detecting flux leakage from defects, the results being recorded on a strip chart. While at Mauritius, the drill pipe was Tuboscoped for the first time in six months, and 58 joints were marked as questionable. These joints were broken out of the string while at sea, cleaned internally, and further inspected with a boroscope tool (an internally-lighted optical instrument). Pit depths were than determined by an externally-applied ultrasonic probe. Of these 58 joints, only 11 were ultimately rejected; the remaining 47 were placed in the bottom of the string. 


\section{Other Equipment}

\section{Power Sub}

For DSDP operations, a power sub rather than the more conventional rotary table is used to transmit rotary motion to the drill pipe. The sub, a Bowen Model PS-4, is essentially a hydraulic motor driving a large ring gear attached to the drill pipe. Table 3 contains the torque and speed ratings, based upon a hydraulic system capable of $200 \mathrm{gpm}$ at $3750 \mathrm{psi}$.:

TABLE 3

Power Sub Ratings

\begin{tabular}{lrc}
\hline Gear & $\begin{array}{c}\text { Torque } \\
\text { (ft-lb) }\end{array}$ & $\begin{array}{c}\text { Max Speed } \\
\text { (RPM) }\end{array}$ \\
\hline 1st & 28,000 & 55 \\
2nd & 17,000 & 90 \\
3rd & 12,500 & 125 \\
4th & 7,900 & 200 \\
\hline
\end{tabular}

During Leg 25, the Bowen power sub operated without incidence. It was normally run at 50 RPM and 10,000 ft-lb of torque and accumulated $164 \mathrm{hr}$ of rotating time. Initial pipe makeup and final spinning-out of joints during drilling and coring also worked quite well.

\section{Precision Depth Recorder}

Water depth is initially determined with the sonic Precision Dejth Recorder (PDR), corrected to the particular area of operation by Matthews tables. Two independent readings are made to eliminate errors and avoid the possibility of running into the ocean floor with the drill string. After spudding, averaged drill pipe measurements are used for mudline-to-Kelly bushing distances and hole depths, without allowing for drill pipe stretch. Correlation between PDR and drill pipe measurements (during spudding) was inconsistent without any obvious reason, such as vessel motion and type of bottom. Normal differences ranged from 0 to 75 feet $(22$ $\mathrm{m})$, with one variation of 280 feet $(85 \mathrm{~m})$ (Hole 244 , Zambezi Canyon, attributed to phantom reflections from a sloping bottom). In nine out of ten cases, the PDR readings gave water depths less than drill pipe measurements. In the broad sense, differences seem to increase with water depth. These variations do not create any serious problem, but there is some feeling of apprehension when spudding without knowing the precise depth to bottom. The initial punch core is particularly difficult to take when the sediments are soft, the drill string is long, and the vessel is heaving; then, the weight indicator is not sensitive enough to provide a definite "kick", signaling that bottom has been reached.

\section{Inclinometer}

The tool used to measure hole deviation (from vertical) was an Eastman self-checking double-punch mechanical type instrument. Its clock allows sufficient time for the instrument to reach the bottom of the drill string before the first of two plumb bob scribe marks is recorded on a disk.
Inclinometer measurements were taken on Leg 25 as conditions permitted. This was done in 6 of the 13 holes, with no more than 2 measurements per hole. The two readings on each disk normally varied by several degrees and required averaging, except for one time when drill pipe motion was negligible. Several readings showed $2^{\circ}$ and $8^{\circ}$ on the same disk. Although hole deviation was not considered a problem and these measurements are satisfactory as approximate indicators, more precise measurement would require some means of immobilizing the drill string, such as a heave-compensating device.

Instrument runs were made by two methods: (1) using the instrument in a regular inner core barrel, taking readings just prior to coring (approximately $1 \mathrm{~m}$ of core is lost); or (2) taking readings simultaneously with heat flow measurements. In the latter case, the inclinometer is installed in the top of the core barrel containing the heat flow instrument. Although either method is acceptable, readings taken just prior to coring are more desirable; the inner barrel can free-fall to the bottom rather than being lowered on the coring line as is required by the heat flow instrument. A disadvantage is that the disk becomes "scuffed," apparently from contact with the plumb bob while in motion, making it difficult to read.

\section{Heat Flow Instrument}

The instrument for recording bottom hole temperatures has two components: a 3/4-in. x 18-in. temperatureindicating thermistor probe; and a temperature (tape) recording package. A timer delays recording while the instrument is lowered to the bottom on the coring line.

The instrument was not available for service until the fifth hole of Leg 25. Of the nine holes remaining, measurements could be made in only three. Three holes were abandoned shortly after spudding, another after encountering sand at 203 meters, and two holes had seas which were too rough. On those holes where measurements were taken (Sites 242, 248 and 249), acceptable data were obtained.

This heat flow instrument is locked into an inner barrel with the core catcher dogs (to prevent downward travel). Upward travel is prevented by pipe spacer containing a baffle plate. The inner barrel is lowered to bottom by wireline and locked into the outer core barrel. During recording, the bit is set on bottom with approximately $10,000 \mathrm{lb}$ of weight. Maximum delay prior to temperature recording was $25 \mathrm{~min}$. This posed no problem in shallower waters, but at, or below, 5000 meters depth, temperature recording was started prior to inserting the probe into the formation. This situation was not entirely without merit, as it did allow bottom-water temperatures to be recorded and provided another point on the buildup curve for heat flow data.

The heat flow equipment functioned satisfactorily except on the initial run in Hole 242. There the bottom lock assembly (an aluminum sleeve with a steel washer on top) was lost above the bit. Fortunately, the steel washer was recovered as a portion of the succeeding core, after an inner barrel with center bit had been run to push the assembly through the bit. 


\section{TECHNIQUES}

During the several years of Glomar Challenger operations, the contractor, Global Marine, and the DSDP staff at La Jolla have made substantial contributions toward improving techniques and procedures for deep ocean coring. This does not mean that all activities are presently just routine or that additional improvements are not possible. It does mean that a much smoother and more efficient approach is now being used in reaching scientific objectives.

This section includes plans and procedures developed from past experience and outlined in the Operations Plan manual, together with specific comments on Leg 25 events.

\section{Site Approach and Vessel Positioning}

During Leg 25, the following procedure was typical after arrival at a general site area: airgun profiling was continued at reduced speed ( 5 knots); the most promising site was selected from the profile records; the beacon was dropped while crossing the site at 5 knots; the electronic gear was retrieved, followed by a $180^{\circ}$ turn, to regain the site. The PPI scope was used to home-in on the beacon. Vessel response during these maneuvers was quite good, with the final $180^{\circ}$ turn being made in about five min once the electronic gear had been retrieved. When the beacon reached bottom, the positioning system was checked for reliable operation, the system was "locked" onto the beacon signal, and the ship's position was ultimately verified by satellite navigation. Depth was tentatively established by the Precision Depth Recorder, corrected for the particular area.

During the leg, confused seas gave the positioning system several severe tests, and it responded well except as cited earlier. Operations were not seriously hampered by not being able to operate all four thrusters simultaneously during drilling in deeper waters. Simultaneous operation is not possible because of power limitations and the method of generator assignment.

Whenever an offset hole is drilled, such as Holes $240 \mathrm{~A}$ or $245 \mathrm{~A}$, the vessel does not have to be moved. The drill pipe is just pulled above the mudline and a new hole is spudded. The chance of reentering the old $101 / 8$-in. hole is quite remote.

Moving between two sites that are fairly close (i.e., Sites 243 and 244) can be done without pulling the entire drill string. Pipe is pulled to above the mudline and the vessel is moved at about 1 knot.

\section{Running and Spudding Procedures}

The bottom hole assembly (BHA) and drill string are run at about $2000 \mathrm{ft}(610 \mathrm{~m} / \mathrm{hr})$. The inner (core) barrel is dropped into position before the BHA is run so that a core can be taken as soon as the bit reaches bottom. When the drill string is within 18 meters of bottom (as indicated by PDR readings), the power sub and swivel are attached. Sixty $\mathrm{ft}(18 \mathrm{~m})$ of pipe are then added, and an attempt is made to determine initial contact with the ocean bottom by a "kick" on the weight indicator. If sediments are soft or the vessel is moving, the exact depth of contact is difficult to detect. On contact, the averaged drill pipe measurements from the Kelly bushing to the ocean floor are recorded as well as used for determining coring depths. The drill string is lowered until the bit takes weight or the inner barrel is thought to be filled. The inner barrel is then retrieved and the initial "punch" core removed. Successful punch cores were obtained 50 percent of the time on Leg 25 .

\section{Type Sediments Required}

Past experience has shown that a soft, easily penetrated, and fairly stable sediment cover is best for initial drilling. This provides adequate lateral support for the BHA and prevents equipment loss when harder underlying formations are being drilled or cored. Ideally, this soft sediment cover should equal the length of the Bottom Hole Assembly $(128 \mathrm{~m})$ and be penetrable without drill string rotation or circulation. Fifty meters of this material is considered minimum cover and will support the lower bumper subs and drill collars; any less amount markedly increases the risks of equipment failure and early hole abandonment.

Leg 25 had two excellent examples of these limitations. At Site 244, unstable clay and pebbly sands at the top of the hole forced abandonment after penetration of only 27 meters. The bit and core barrel were lost, having wobbled off the top sub, which was bent and ovalshaped (Figure 2). At Site 247, hard sediments caused abandonment after only 26 meters of penetration, despite $20 \mathrm{~min}$ with bit weights of 10,000 to $20,000 \mathrm{lb}$, circulation with two pumps, and drill string rotation. One bumper sub was found to be bent due to insufficient lateral support (Figure 3).

\section{Running and Retrieving Core Barrel}

As previously stated, the inner core barrel is wireline-retrievable and has a removable plastic tube for core containment. Two inner barrels are used alternately, to increase efficiency of operations. Only about $2 \mathrm{~min}$ elapse from the: time the first core barrel "hits the deck" (after retrieval) until the second is dropped "free fall" down the drill string. As the barrel is dropping, the circulating pump is run slowly, to shorten the time of descent. Seating at the bottom of the drill string is indicated by a momentary increase in pump pressure. The time of descent varies with drill string length and amount of fluid pumped but may take approximately $25 \mathrm{~min}$ for a $17,000 \mathrm{ft}(5150 \mathrm{~m})$ depth. At that depth retrieval takes about $1 \mathrm{hr}$.

During retrieval, it is a good practice to have the pump run slowly and the drill string rotate slightly, to avoid sticking the drill pipe. Successful latching of the overshot on the inner barrel is indicated by the $500 \mathrm{lb}$ overpull required for unseating. Normally, the barrel is recovered on the first attempt. At Site 248, however, the bit plugged temporarily and sand and pipe scale interfered with proper latching. Retrieval was finally accomplished on the fourth try by using a thin-wall overshot.

After the final core at a site has been taken, the inner barrel is dropped down the drill string once again, as insurance that the string is unobstructed for the next hole. Basalt, for example, can fall out of the core barrel during retrieval and become lodged in the drill pipe. 


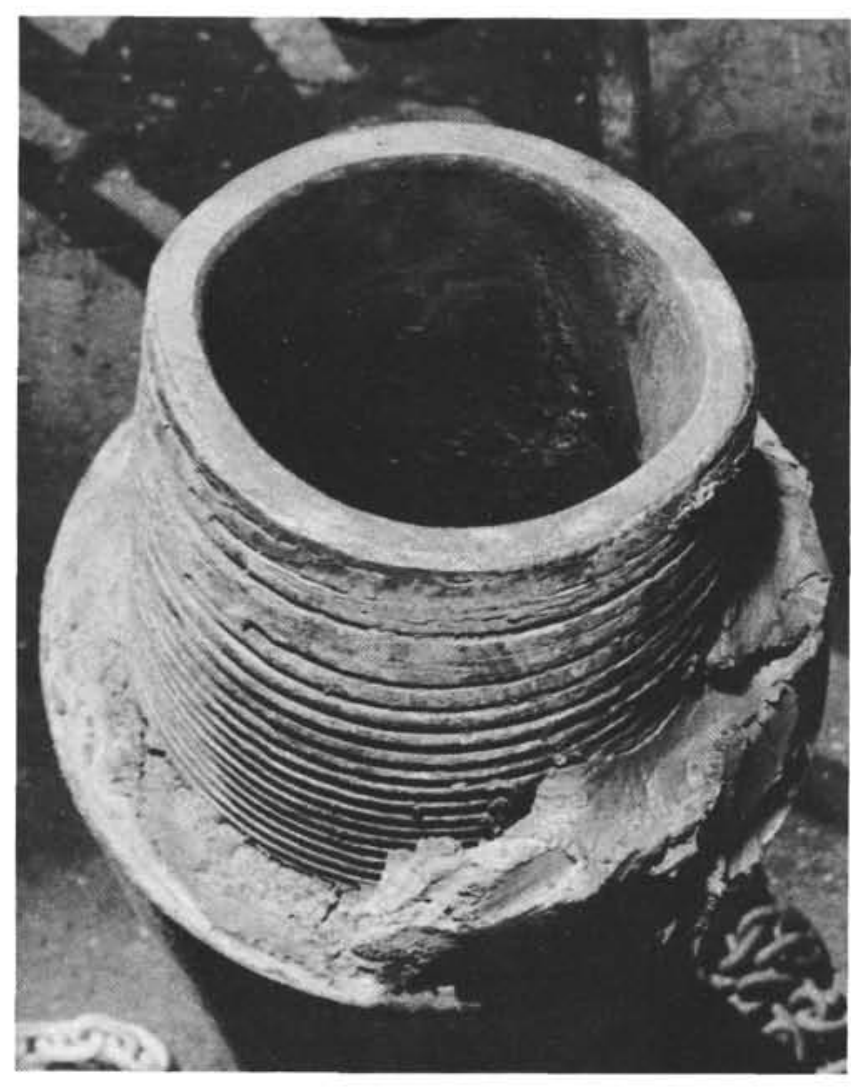

Figure 2. Core barrel and bit lost after wobbling-off top sub (shown). Pin on sub oval-shaped and bent after spudding into unconsolidated sediments (sand, fine loose gravel, pebbles, and silty clay). No lateral support for bottom assembly (Sites 243 and 244).

\section{Coring}

\section{General}

The only depth limitations imposed for coring or drilling relate to hole stability, possibility of encountering hydrocarbons, and the $22,500 \mathrm{ft}$ ( 6860 meters) maximum allowable drill pipe length. Saltwater circulation is used throughout coring, with drilling mud used only to combat swelling or sloughing sediments and on abandonment of holes in certain areas, as outlined by the Safety Panel. Seven of the 13 holes on the leg required mud stabilization. Drilling techniques are rather straightforward: in the upper sediments, full pump SPM without drill string rotation; in the deeper sediments, full pump SPM, with drill string rotation increased from 5 to $70 \mathrm{RPM}$.

\section{Core Recovery}

Overall core recovery for the leg was 57 percent, which is about the average for other DSDP legs. Several problems reduced recovery: sediments whose "binder" material dissolved in water; plastic sock failures due to abrasion and tearing; completely worn-out bits; jammed or gumboencased bits; damaged core catchers which allowed hard, broken formations to drop out of the barrel during retrieval; and collapsed plastic liners. Figure 4 shows observed and/or recorded coring conditions for sites where recovery was good $(77 \%)$, average $(54 \%)$, and poor $(30 \%)$. Vertical bars are shown at various depth datum points for weight, RPM, and torque to indicate a range of values. If one had to draw conclusions on primary reasons for poor recovery from this information, they would be: first, the type of formation being cored; and second, vessel motion (roll and heave) varying the bit weight. Continued improvement in core catchers will help alleviate the former problem, and a heave compensation device should practically eliminate bit weight variation.

\section{Coring Programs}

Intervals cored at the various sites are indicated on Figure 5. The average program was four cores per 100 meters. Time required for each core varied from a few minutes for the soft sediments to as much as 4 hours for the hard basalts.

The technique used for recovery of the slushy unconsolidated type, was the "punch" core procedure. The drill pipe is lowered evenly and steadily, without rotation or pumping, while holding bit weight as constant as possible. Approximately $6 \mathrm{~min}$ is required to fill the inner barrel; any faster action can result in poorer recovery. A plastic sock about $10 \mathrm{in}$. long, extending into the plastic liner and held in place by dog-type core catchers, is used to trap the sediments in the tube. Although past experience with the sock has been very good, Leg 25 experienced a 20 percent failure rate. The sock apparently was sheared by abrasive action of the sediment, traveled to the top of the core barrel, and plugged the check valve. This precluded any core being recovered at all. A flapper-type catcher was used at Site 246 but without success.

Dry, unconsolidated sediments are almost in the same class as slushy types as far as recovery is concerned. Even a minimum of water circulation seems to destroy some cores, and this water sensitivity often causes hole problems (sloughing formations). Experience has shown that the plastic sock normally should not be used in coring these formations, but the formation has to be dry and compactable enough not to fall through the dog-type catchers. In coring this type formation, the bit is lowered and turned slowly (5-10 RPM) without fluid being pumped until the bit weight and torque make fluid circulation necessary. Then the pump is run at 5-10 SPM until circulation is "broken." At that instant the pump is shut off. During this time, the bit is still being rotated slowly with as constant a weight as possible, in the range of $5000-15,000 \mathrm{lbs}$. After circulation is "broken," the penetration rate increases and the torque decreases, and the preceding coring cycle is repeated.

Figure 5 shows that the depth at which it was necessary to start initial rotation of the bit during coring on Leg 25 varied from 25 to 75 meters, averaging about 50 meters. Initial "breaking of circulation" was done at 50 to 175 meters and averaged 100 meters. Core recovery averaged 65 percent from the mudline down through "break in circulation" depths (i.e. where full circulation was required).

Unconsolidated sediments such as foram nanno ooze are probably the easiest to core and have the highest recovery rate. The coring procedure is similar to that previously 


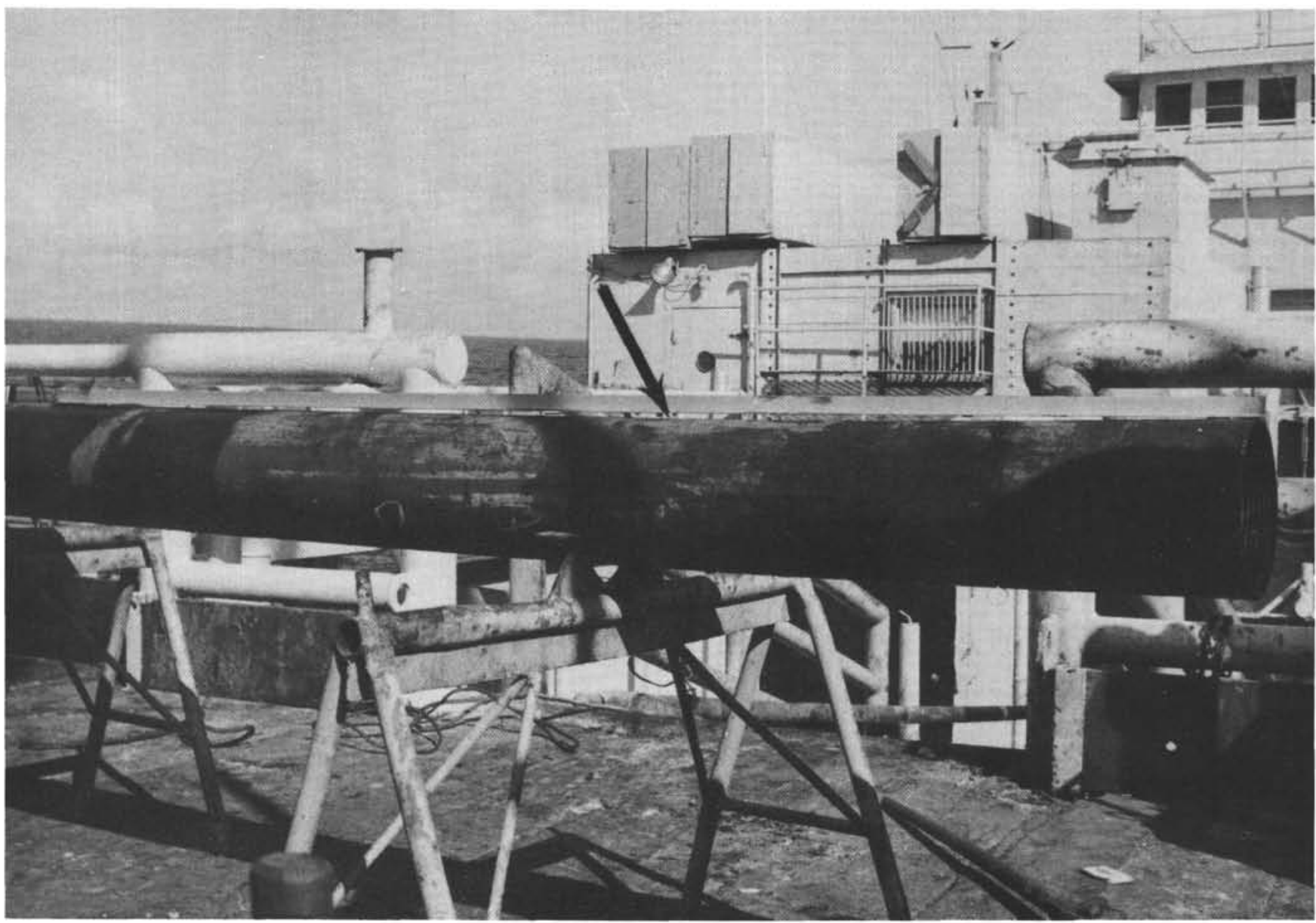

Figure 3. Arrow indicates maximum alignment of bent bumper sub after drilling on shallow, hard sediment and bumper sub laterally unsupported. (Site 247).

outlined for dry, unconsolidated sediments. A rather striking example of the influence of sediment type on recovery rates is provided by Hole 249 . The upper 284 meters of foram nanno ooze had a recovery rate of 94 percent, while the rate for the bottom 128 meters of silty clay, siltstone, and limestone was only 43 percent.

Full-time circulation of one pump is required for coring as hole depths increase and sediments become harder and more compact. This initial full circulation occurred at depths ranging from 140 to 310 meters, averaging 200 meters. Pump pressures ranged from 100 psi for the softer, shallower sediments to $600-800 \mathrm{psi}$ for the deeper harder sediments.

Core recovery from the "full circulation" depths to total depths averaged 50 percent, or about 15 percent less than the intervals above these depths. Other parameters, such as bit weight, bit RPM, and drill string torque, generally increase with depth, while penetration rates decrease. Table 4 gives some of the coring parameters for intervals from initial full-time pump circulation to total depth.

Average pump circulation rates used during coring are almost diametrically opposed to those used in normal drilling, where the intent is to sweep the hole as clean of cuttings as possible. To accomplish this cleaning action, industry experience has shown that fluid velocities through the bit jet nozzles should be approximately $70 \mathrm{~m} / \mathrm{sec}$ and annular velocities, $37.55 \mathrm{~m} / \mathrm{min}$. Table 5 lists the velocities normally used during coring. These are obviously low when compared to hole cleaning velocities. More specifically however, it may indicate that cuttings not swept out of the hole during coring settle during core barrel retrieval and therefore may appear in subsequent cores, along with sediments that slough from the upper portion of the hole.

In certain formations, applying too much bit weight will plug some or all of the jets, leaving only the small area between the inner and outer core barrels for fluid circulation. This further aggravates hole cleaning problems and may cause early hole abandonment if not corrected.

The harder formations, such as basalt and chert, present special problems. Indicators such as increased torque, decreased penetration, and (in the case of basalt) derrick and tool shaking, are commonly encountered. Bit life is severely limited in this type of service as evidenced by the attached photograph (Figure 6) showing the bit used in drilling Holes 240 and $240 \mathrm{~A}$. Generally, the plastic tube is removed from the inner barrel for harder formations as these tend to cause the tube to collapse or the core to become so tightly lodged as to prevent the taking of a full core. Core catchers are also a problem. Several times when coring basalt, the dogs (of the dog-type) were sheared off while the slip-type was driven up into the inner barrel.

A successful coring procedure for the harder formations is to maintain light contact for a timed period while rotating at about 40 to $50 \mathrm{RPM}$; then increasing the bit 


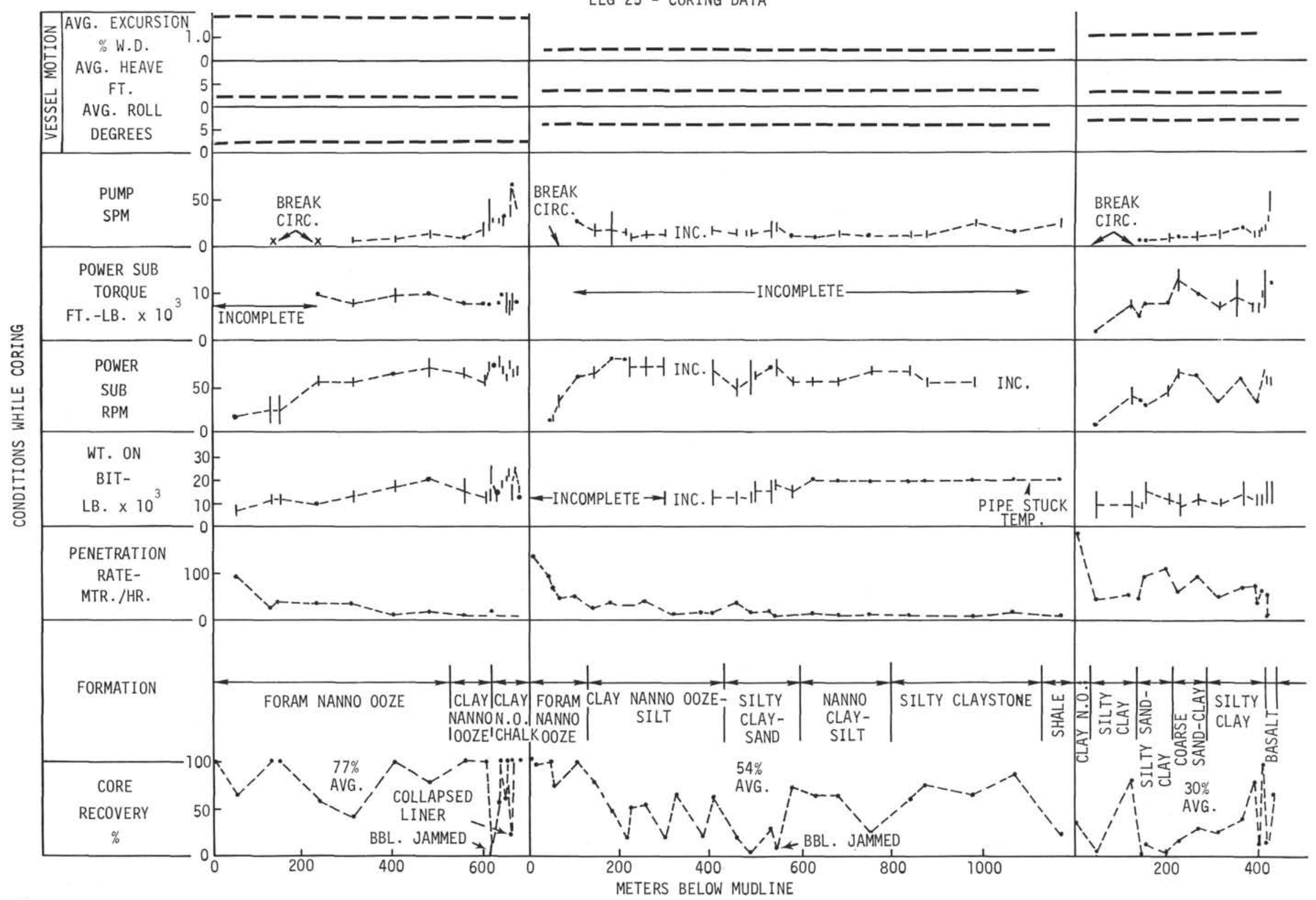

Figure 4. Leg 25 Coring Data. 


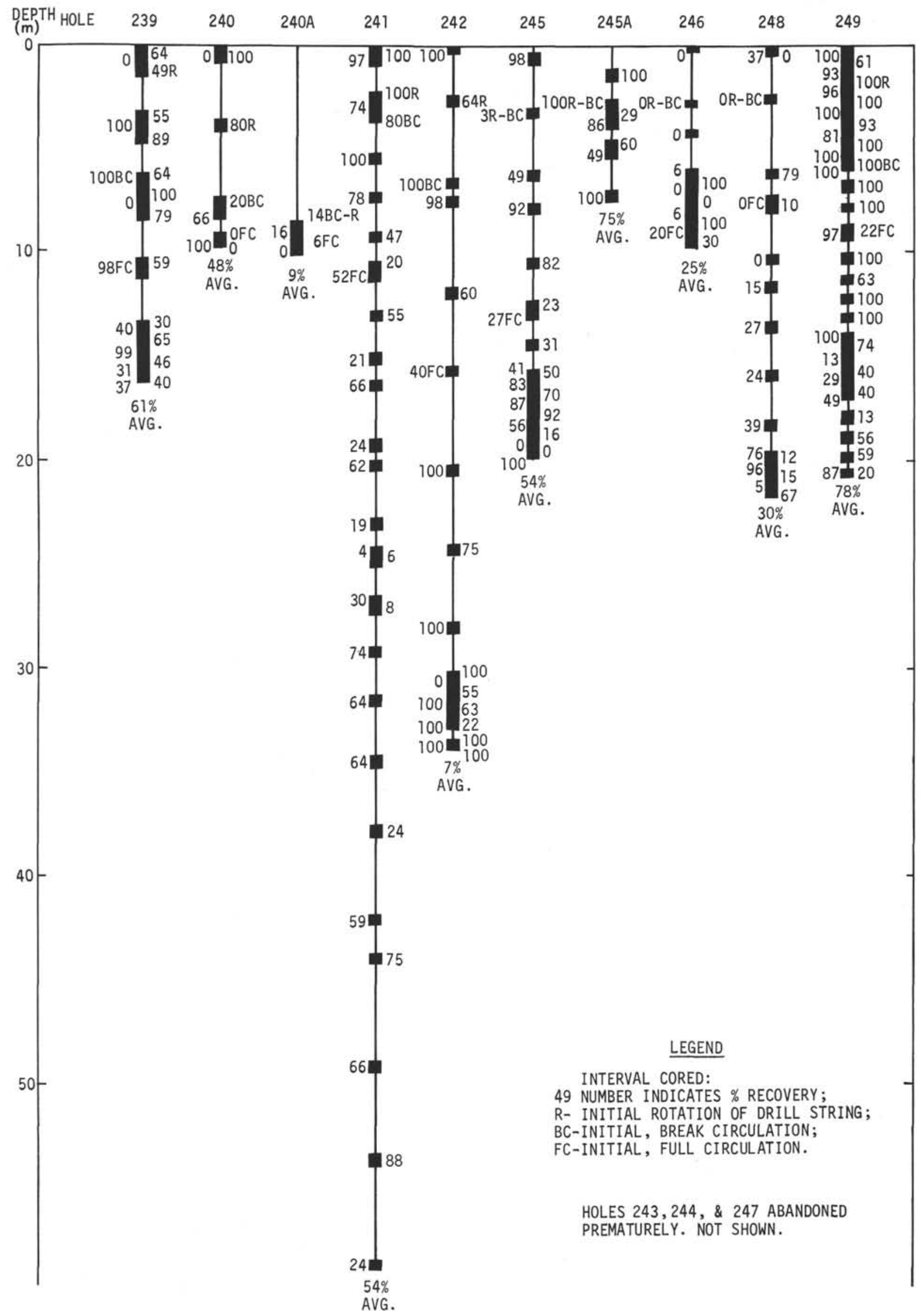

Figure 5. Leg 25-Coring Program Legend: Note: Hole 243, 244, and 247 abandoned prematurely. Not shown. - Interval cored; $49=$ Number Indicated \% Recovery; $R=$ Initial Rotation of Drill String; $B C=$ Initial, Break Circulation; FC = Initial, Full Circulation. 
TABLE 4

Coring Parameters Below Full Circulation Depths

\begin{tabular}{llrrrrrrr}
\hline & & \multicolumn{7}{c}{ Hole } \\
\cline { 3 - 9 } & & & \multicolumn{7}{c}{ 239 } & 241 & 242 & 245 & 246 & 248 & 249 \\
\cline { 3 - 9 } Total Depth (m): & & 326 & 1174 & 676 & 397 & 203 & 434 & 412 \\
F.C. Depth (m): & & 215 & 220 & 310 & 260 & 175 & 140 & 165 \\
\hline Bit Wt. (1000 lbs) & Max. & - & 20 & 26 & 24 & 20 & 20 & 20 \\
& Avg. & - & 15 & 18 & 15 & 12 & 12 & 15 \\
RPM & Max. & 80 & 80 & 80 & 80 & 80 & 70 & 80 \\
& Avg. & 70 & 65 & 65 & 65 & 50 & 60 & 60 \\
Torque (1000 ft-lbs) & Max. & - & - & 11 & 14 & 14 & 16 & 10 \\
& Avg. & - & - & 8 & 8 & 11 & 10 & 9 \\
SPM & Max. & - & 55 & 65 & 40 & 20 & 55 & 55 \\
& Avg. & - & 20 & 30 & 25 & 10 & 20 & 30 \\
Pene. Rate (m/hr) & Max. & 60 & 40 & 40 & 40 & 20 & 110 & 60 \\
& Avg. & 20 & 20 & 15 & 15 & 10 & 60 & 20 \\
Recovery (\%) & & 54 & 44 & 75 & 50 & 25 & 30 & 59 \\
\hline
\end{tabular}

TABLE 5

Circulating Fluid Velocities

\begin{tabular}{cccccc}
\hline & & \multicolumn{2}{c}{ Jet Velocity } & & \\
\cline { 3 - 4 } SPM & GPM & $\begin{array}{l}\text { 3-Jet Bit } \\
(\mathrm{m} / \mathrm{sec})\end{array}$ & $\begin{array}{c}\text { 4-Jet Bit } \\
(\mathrm{m} / \mathrm{sec})\end{array}$ & $\begin{array}{c}\text { Ann. Vel. } \\
(\mathrm{m} / \mathrm{min})\end{array}$ & $\begin{array}{c}\text { Time }^{\mathrm{a}} \\
(\mathrm{min})\end{array}$ \\
\hline 10 & 80 & 11 & 8 & 8 & 13 \\
20 & 160 & 21 & 16 & 16 & 6 \\
30 & 240 & 32 & 24 & 23 & 4 \\
40 & 310 & 41 & 31 & 30 & 3 \\
50 & 380 & 50 & 38 & 38 & 3 \\
60 & 460 & 61 & 46 & 45 & 2 \\
\hline
\end{tabular}

${ }^{\text {a }}$ Time for cutting to travel $100 \mathrm{~m}$ up hole.

weight to $25,000-30,000 \mathrm{lbs}$ and moving the bumper sub action to a top bumper sub. Circulation rates do not appear to be critical.

\section{CONCLUSIONS}

Success in coring operations depends not only upon equipment and techniques, but also upon personnel. Global Marine's personnel are to be highly commended for their skill in drilling and marine operations and for their cooperation, helpfulness, and fine attitude during trying times imposed by the environment. Additionally, members of the scientific group were not only highly professional, conscientious, and enthusiastic, but also a real delight for their cooperation, sense of humor, and understanding nature, particularly when technical problems precluded fulfillment of scientific objectives.

Since the start of DSDP operations in 1968, many drilling tools and techniques have been tried. Improvements have generally been the result of evolution rather than dramatic "breakthroughs." Today, as then, changes are continually being made to improve efficiency and bring about greater realization of scientific objectives. As efficiencies and techniques are improved, more demanding scientific goals can be set, and a new cycle of development is thereby set in motion.

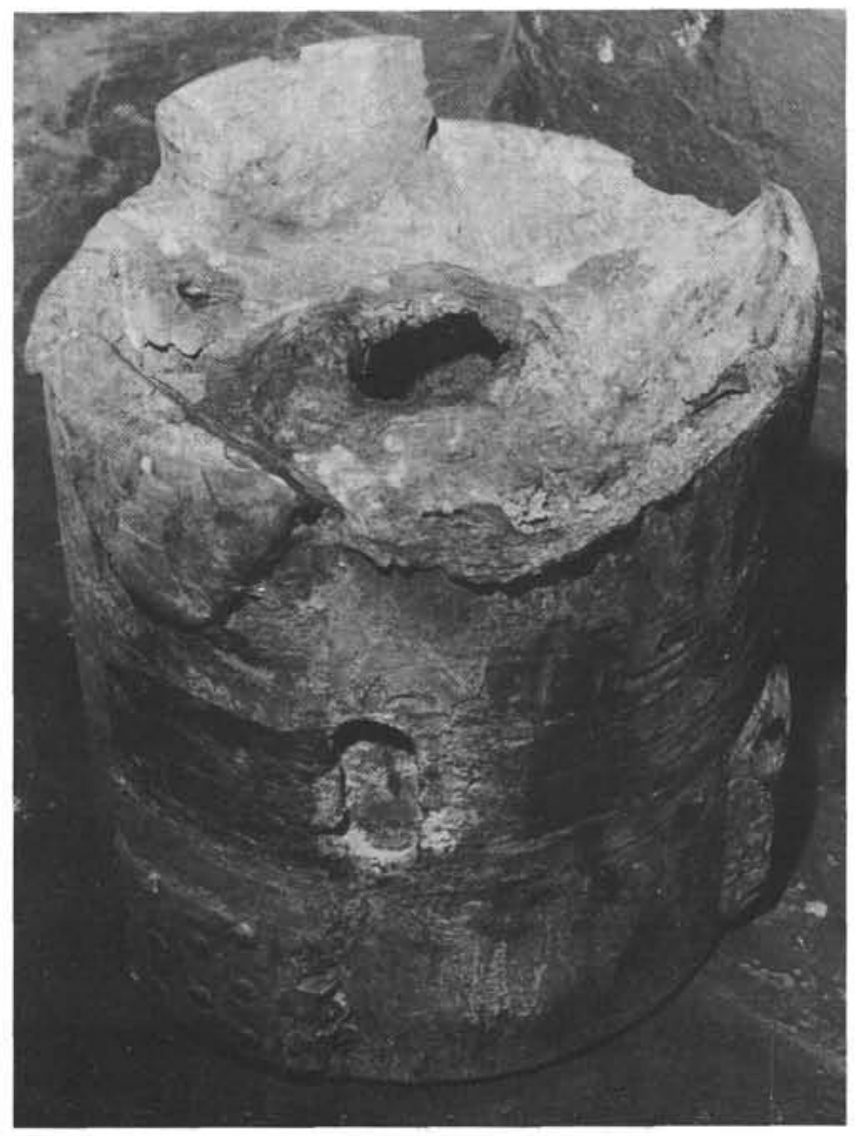

Figure 6. Originally a 3 cutter, non-sealed bearing bit. Total rotating time 13 hours, including 6 hours on basalt. (Site 240). 